\title{
Eosinófilos e IL-5 - Novos horizontes no tratamento da asma e outras doenças eosinofílicas
}

\section{Eosinophils and IL-5 - New horizons for the treatment of asthma and other eosinophilic diseases}

Rev Port Imunoalergologia 2020;28 (4):207-2I6

Gonçalo Martins dos Santos, Sara Prates, Paula Leiria-Pinto

Serviço de Imunoalergologia, Centro Hospitalar Universitário de Lisboa Central, Lisboa

\section{RESUMO}

Os eosinófilos participam na defesa do hospedeiro como células do sistema imune inato, mas estão também associados a diversas patologias. Recentemente, tem-se questionado se a acumulação destas células em patologias associadas a eosinofilia tem apenas efeitos patológicos ou se desempenha também um papel nos mecanismos de resposta homeostáticos. A interleucina-5 (IL-5) é a principal citocina envolvida na produção e atividade dos eosinófilos. Os anticorpos monoclonais anti-interleucina-5 (mepolizumab e reslizumab) e antirrecetor da IL-5 (benralizumab) encontram-se atualmente aprovados para o tratamento da asma grave de fenótipo eosinofílico, proporcionando benefícios a nível da redução de sintomas e melhoria da qualidade de vida destes doentes. No futuro, é expectável um aumento da abrangência das indicações terapêuticas destes fármacos. Neste artigo de revisão pretende-se reunir a mais recente evidência referente ao papel dos eosinófilos e da IL-5 na resposta inflamatória e às principais características dos anticorpos monoclonais anti-IL-5/IL-5R.

Palavras-chave: Anticorpos monoclonais anti-IL-5, asma brônquica, benralizumab, eosinófilo, interleucina-5, mepolizumab, reslizumab. 


\section{ABSTRACT}

Eosinophils participate in the host defense as innate immune cells, although they are also associated with many diseases. Recently, it has been questioned whether the increased number of these cells in conditions characterized by eosinophilia is limited to a harmful event or if it is also involved in a homeostatic response. Interleukin-5 (IL-5) is the major cytokine involved in eosinophil production and activity. Anti-interleukin-5 (mepolizumab and reslizumab) and anti-interleukin-5 receptor (benralizumab) monoclonal antibodies are currently approved for the treatment of severe eosinophilic asthma phenotype, providing benefits in reducing symptoms and improving quality of life of these patients. In the future, an increased range of therapeutic indications for these drugs is expected. In this review we aimed to sum up the current and new evidences about the role of the eosinophils and IL-5 in the inflammatory response and the main features of the anti-IL-5/IL-5R monoclonal antibodies.

Key words: Anti-IL-5 monoclonal antibodies, asthma, benralizumab, eosinophil, interleukin-5, mepolizumab, reslizumab

\begin{tabular}{|ll|}
\hline & Lista de acrónimos e abreviaturas \\
\hline ACQ - Asthma Control Questionnaire & IL - Interleucina \\
AQLQ - Asthma Quality of Life Questionnaire & IL-5R - Recetor da interleucina 5 \\
C/EBP - CCAAT/enhancer binding protein & JAK2 - Janus Kinase 2 \\
CCR3 - C-C motif chemokine receptor 3 & LFA-I - Lymphocyte function-associated antigen I \\
CD - Cluster of differentiation & Linfócitos TH - Linfócitos T helper \\
Células NK - Células natural killer & LT - Linfócitos T \\
ECP - Eosinophil cationic protein & MAIC - Matching-ajusted indirect comparison \\
EDN - Eosinophil-derived neurotoxin & MBP - Proteína básica major \\
EPX - Eosinophil peroxidase & MEK - Mitogen-activated protein kinase \\
ERK - Extracellular signal-regulated kinases & NaCI - Cloreto de sódio \\
FDA - Food and Drug Administration (EUA) & PAF - Platelet-activating factor \\
FEV - Forced expiratory volume in I second & PSGL-I - P-selectin glycoprotein ligand \\
FoxP3 - Forkhead box P & RafI - RAF proto-oncogene serine/threonine-protein kinase \\
GATA-I - GATA-binding factor I & Ras - Rat sarcoma viral \\
GI - Gastrointestinal & Siglec8 - Sialic acid-binding immunoglobulin-like lectin 8 \\
GINA - Global Initiative for Asthma & STATI - Signal transducer and activator of transcription I \\
GM-CSF - Granulocyte-macrophage colony-stimulating factor & SYK - Spleen tyrosine kinase \\
ICAM-I - Intercellular Adhesion Molecule I & VCAM-I - Vascular cell adhesion molecule \\
IgA - Imunoglobulina A & VLA-4 - Very Late Antigen-4 \\
\hline
\end{tabular}

\section{INTRODUÇÃO}

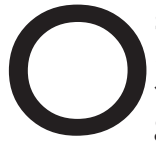
sistema imunitário é constituído por um conjunto de células e fatores solúveis que interagem entre si de forma complexa, organizados no que se convencionou considerar dois braços - o sistema imune inato e o sistema imune adaptativo - estreitamente interrelacionados. A resposta imune inata é mediada por várias células, entre as quais as células den- dríticas, células natural killer (NK), neutrófilos, macrófagos, mastócitos e eosinófilos ${ }^{1,2}$. Estas células vão, além de desencadear uma resposta imune inicial, participar na ativação e modulação da resposta imune adquirida, desempenhando também diversas funções na sua fase efetora. $\mathrm{O}$ sistema imune adaptativo assegura uma resposta mais específica e a produção de células de memória imunitária, mediada pela interação entre as células T, B e células apresentadoras de antigénio ${ }^{2,3}$. 
Neste artigo de revisão pretende-se reunir a mais recente evidência referente ao papel dos eosinófilos e da interleucina (IL)-5 nas respostas inflamatória e homeostática e às principais características dos anticorpos monoclonais anti-interleucina-5 e antirrecetor da interleucina-5 (IL-5R) recentemente introduzidos no nosso mercado.

\section{EOSINÓFILOS}

\section{Produção}

Os eosinófilos são células com origem na medula óssea pertencentes à linhagem dos granulócitos. $\bigcirc$ seu ciclo de vida pode ser dividido em três fases, que decorrem sucessivamente na medula óssea, no sangue periférico e nos tecidos celulares periféricos ${ }^{2}$.

A produção de eosinófilos na medula óssea ocorre a partir de células estaminais pluripotentes que se diferenciam em progenitores CD34+, comuns a basófilos e eosinófilos. O posterior desenvolvimento nas colónias produtoras de eosinófilos está dependente de uma cascata de eventos interdependentes, a envolver pelo menos três classes de fatores de transcrição: GATA-I, PU-I e proteínas C/EBP2,4-6.

Além dos fatores referidos, na eosinofilopoiese estão também implicadas outras moléculas, nomeadamente o fator de estimulação de colónias de granulócitos/macrófagos (GM-CSF), a IL-3 e a IL-5. Importa salientar que, ao contrário dos dois primeiros, a IL-5 promove apenas a diferenciação da linhagem dos eosinófilos, não participando no processo de diferenciação de outras linhagens ${ }^{4}$.

Este processo ocorre durante aproximadamente uma semana, ficando parte dos eosinófilos formados armazenados na medula óssea. Posteriormente, em resposta a vários estímulos, como a IL-5, são rapidamente libertados e exercem a sua acção nos locais de inflamação ${ }^{4}$.

\section{Migração para os tecidos}

O eosinófilo é uma célula que reside essencialmente nos tecidos (semivida de 2 a 5 dias), circulando apenas em pequena quantidade na corrente sanguínea $(0$ - 500 células $/ \mathrm{mm}^{3}$, com uma relação $100: 1$ ), tendo uma semivida em circulação de 8-18 horas ${ }^{2,4}$.

Os eosinófilos estão, assim, normalmente presentes nos tecidos, especialmente naqueles com interfaces mucosas com o ambiente exterior, ou seja, nos tratos gastrointestinal (com exceção do esófago), respiratório e genitourinário baixo. Além disso, podem também ser encontrados no timo, na glândula mamária e no útero ${ }^{2,4}$.

A mobilização dos eosinófilos da corrente sanguínea para os locais de inflamação é regulada por diversos estímulos quimioatrativos e por várias moléculas de adesão que, com diferentes graus de afinidade, medeiam os processos de rolamento, adesão e transmigração endoteliais. O processo de rolamento ocorre através da ligação de glicoproteínas específicas (PSGL-I) do eosinófilo às selectinas presentes no endotélio vascular; o processo de adesão endotelial é depois mediado pela ligação de integrinas da superfície do eosinófilo (VLA-4 e LFA-I ou CDII/CDI8) às moléculas de adesão do endotélio (respetivamente VCAM-I e ICAM-I e ICAM-2) ${ }^{2,4,5,7}$. Após a adesão, ocorre a transmigração endotelial para o local da inflamação, dependente de várias moléculas, como o fator de ativação plaquetária (PAF), anafilotoxinas do complemento ( $\mathrm{C} 5 \mathrm{a}$ e $\mathrm{C} 3 \mathrm{a}$ ) e ainda várias quimiocinas, sendo as principais as eotaxinas (eotaxina-I, eotaxina-2, eotaxina-3), que atuam no eosinófilo, predominantemente através do recetor $\mathrm{CCR} 3^{2,4,5}$.

\section{Morfologia e mediadores produzidos}

Os eosinófilos apresentam um núcleo bilobado e contêm diversos grânulos citoplasmáticos que se podem classificar em primários, secundários ou específicos, pequenos grânulos e microgrânulos ou vesículas secretoras ${ }^{2}$. Contêm também os chamados corpos lipídicos, local de síntese dos leucotrienos ${ }^{2}$.

Os eosinófilos têm uma grande capacidade de produzir os mediadores envolvidos nas suas funções biológicas, nomeadamente proteínas dos grânulos (proteína básica major-MBP, peroxidase do eosinófilo-EPX, proteína ca- 
tiónica do eosinófilo-ECP e neurotoxina derivada do eosinófilo-EDN), mediadores lipídicos, produtos oxidativos, enzimas, citocinas, quimiocinas e fatores de crescimento ${ }^{2}$.

As proteínas dos grânulos possuem efeitos antiparasitários, antitumorais e antibacterianos, sendo no entanto citotóxicas para o epitélio respiratório e outras células do hospedeiro ${ }^{2}$. Deste modo, estas proteínas associam-se, tanto à defesa do hospedeiro como a lesão e consequente dano tecidual, estando assim relacionadas com diversas patologias, entre as quais a asma brônquica.

Entre os principais mediadores lipídicos produzidos pelos eosinófilos estão os leucotrienos $\mathrm{C} 4$, que vão promover a broncoconstrição, a secreção de muco, alterar a permeabilidade vascular e promover a infiltração eosinofílica e neutrofílica ${ }^{2}$. Salienta-se também a produção de citocinas, como GM-CSF, IL-3 e IL-5, e as eotaxinas que, como referido, estão envolvidas na produção, diferenciação e ação do próprio eosinófilo através da promoção da sobrevivência e amplificação da sua resposta biológica. Os eosinófilos originam também outros fatores que contribuem para os processos de reparação, remodelação e fibrose tecidular ou que participam na regulação de outras respostas imunes ${ }^{4}$. Adicionalmente, expressam uma grande quantidade de recetores na superfície celular, através dos quais comunicam com o ambiente envolvente e com as outras células ${ }^{4}$.

\section{A INTERLEUCINA-5}

A IL-5 é uma citocina produzida por células linfoides inatas tipo 2, linfócitos Th2, células T CD8 $8^{+}$, células NK e também por outros leucócitos, incluindo os próprios eosinófilos ${ }^{1,5,7-9}$. Esta citocina estimula especificamente a produção de eosinófilos na medula óssea. A sua atividade biológica resulta da ativação do seu recetor nos eosinófilos, constituído por uma subunidade alfa (CDI25) e uma subunidade beta. A ligação da IL-5 à subunidade alfa do recetor provoca a fosforilação das tirosinacinases
JAK2 e LYN e SYK, com consequente ativação das vias do STATI e Ras-RafI-MEK-ERK, respetivamente, promovendo a transcrição de genes envolvidos no crescimento, sobrevivência e ativação dos eosinófilos² ${ }^{2}$.

Dos vários efeitos biológicos exercidos pela IL- 5 destacam-se promoção da diferenciação e proliferação do progenitor dos eosinófilos na medula óssea, com o consequente aumento da produção de eosinófilos, estimulação da ativação, sobrevivência e estabilização dos eosinófilos, promoção da quimiotaxia dos eosinófilos, estimulação/amplificação da função biológica efetora dos eosinófilos, estimulação da produção de leucotrienos pelos eosinófilos, regulação da adesão e migração transendoteliais dos eosinófilos ${ }^{10}$.

Deste modo, depreende-se que a IL-5 é um estímulo forte para a produção e ativação dos eosinófilos e, consequentemente, para a ocorrência de lesão do epitélio respiratório no contexto das doenças respiratórias eosinofílicas.

\section{NOVAS PERSPETIVAS SOBRE O PAPEL DO EOSINÓFILO}

\section{Eosinófilos homeostáticos e eosinófilos inflamatórios}

Os eosinófilos integram o sistema imune inato e, para além da sua reconhecida capacidade de destruir parasitas multicelulares, possuem ação antibacteriana, antifúngica e antiviral". Podem também funcionar como células apresentadoras de antigénio, processando os antigénios e estimulando as células $T$, conduzindo à sua proliferação e à libertação de citocinas ${ }^{12}$.

A evidência reunida na última década sugere que 0 papel dos eosinófilos poderá ser bastante mais abrangente, não se limitando apenas às funções de defesa. Estes são cada vez mais reconhecidos como possuindo um papel fundamental na modulação das respostas imune e inflamatória, tanto local como sistémica, e em diversos processos fisiológicos que implicam reparação ou remo- 
delação tecidular ${ }^{12,13}$. Estas funções de regulação imunitária e de remodelação ou reparação tecidular poderão explicar a presença de eosinófilos em vários tecidos (como a mucosa do trato gastrointestinal, o timo, o endométrio, a glândula mamária) em condições basais, ou seja, na ausência de reação inflamatória ${ }^{12-14}$.

Estudos em humanos, e especialmente em ratinhos, sugerem a existência de pelo menos dois fenótipos de eosinófilos: os eosinófilos residentes nos tecidos ou homeostáticos $(\mathrm{EoH})$ e os eosinófilos inflamatórios $(\text { Eol })^{14-16}$. Ambos os subtipos são produzidos na medula óssea, no entanto a produção de EoH ao contrário da de Eol, é independente da ação da IL-5 ${ }^{14,15}$. Os eosinófilos homeostáticos apresentam, em geral, o fenótipo típico do eosinófilo expressando moléculas de superfície, como CCR3, Siglec8 (SiglecF em ratinhos) e CDI25 (a subunidade alfa do recetor da IL-5) ${ }^{14,16}$. No ratinho é possível identificar as duas populações diferentes de eosinófilos circulantes - os EoH, com núcleo em anel e expressando CD62L, e os Eol, com núcleo lobulado e expressão de CDI0I, mas não CD62L $L^{14}$. Também no pulmão, tanto do ratinho como do humano, foi possível identificar as duas populações de eosinófilos. No caso concreto do pulmão humano, em indivíduos sem asma, os EoH residentes no parênquima apresentam o fenótipo Siglec $8^{+} C D 62 L^{+} I L 3 R^{10}$, enquanto os Eol presentes na expetoração de doentes com asma apresentam um fe-

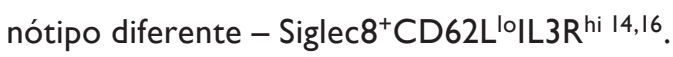

No estado de equilíbrio basal, os eosinófilos migram rapidamente da corrente sanguínea para os tecidos onde vão exercer amplas funções biológicas. $O$ seu recrutamento para os tecidos pode depender, ou não, da produção local de IL-5, segundo o tipo de tecido (independente de IL-5 no pulmão, parcialmente dependente no trato gastrointestinal e útero, totalmente dependente no tecido adiposo) ${ }^{14}$. Tanto em ratinhos como em humanos, a grande maioria dos EoH pode ser encontrada no trato GI (exceto esófago), onde promovem o switch de classe para IgA e a manutenção de uma população de plasmócitos produtores de IgA; participam ainda no desenvol- vimento das placas de Peyer e na produção de muco no intestino delgado ${ }^{15,16}$. Foi também demonstrada a sua capacidade para induzir a diferenciação de LT naive em $\mathrm{LT}$ reguladores Foxp $3^{+}$e de suprimir a diferenciação de LTh $17^{14}$. No timo participam na seleção negativa das células T, contribuindo para o desenvolvimento da tolerância central ${ }^{15,16}$. Estudos no ratinho sugerem também um papel na homeostasia do metabolismo da glicose e no desenvolvimento do tecido adiposo ${ }^{15,16}$ e, ainda, na preparação do útero para a futura gravidez e na regulação do desenvolvimento da glândula mamária'14,15.

\section{Eosinófilos e o microambiente pulmonar}

A mucosa pulmonar está continuamente exposta a alergénios e moléculas imunoestimuladoras do ambiente exterior, pelo que o sistema imune inato pulmonar desenvolveu estratégias para tolerar esses estímulos e minorar o desenvolvimento de respostas inflamatórias ${ }^{15}$. Estudos em modelo animal revelaram a presença, em condições basais, de uma população de EoH distribuída no parênquima pulmonar e de uma população distinta de Eol, de localização peribrônquica, recrutada apenas após indução de inflamação alérgica ${ }^{10}$. A nível pulmonar, existem evidências crescentes de que os EoH possuem a capacidade de minorar o desenvolvimento de uma resposta Th2 contra os alergénios inalados, contribuindo para a imunorregulação da homeostasia pulmonar ${ }^{13,15}$. Estes EoH, contrariamente aos Eol, são independentes da ação da IL-5, pelo que o seu número permanece inalterado, tanto na presença de inflamação alérgica como possivelmente sob tratamento com antagonistas da IL-5//L-5R ${ }^{15}$. Os Eol são recrutados para os locais onde ocorre a resposta mediada por células Th2 de forma dependente da IL-5, participando na eliminação dos parasitas extracelulares, mas também na exacerbação da inflamação ${ }^{15,16}$.

Um estudo recente demonstrou que os eosinófilos têm a capacidade de capturar vários vírus respiratórios, diminuindo a sua infeciosidade ${ }^{17}$. Mostrou ainda que em doentes com asma, após depleção dos eosinófilos com anticorpos anti-IL-5, a inoculação nasal com rinovírus-16 
resultou no aumento da carga viral, em comparação com doentes cujos eosinófilos não foram depletados. $\mathrm{O}$ aumento da carga viral após tratamento com anticorpos anti-IL-5 é sugestivo de um papel antiviral para os Eol (dependentes da IL-5) e não para os EoH (independentes da IL-5) ${ }^{17}$. Contudo, são necessários estudos adicionais, especialmente em humanos, para clarificar a contribuição dos EoH e dos Eol e o impacto das terapêuticas anti-IL-5/ /IL-5R na resposta antiviral ${ }^{17}$.

Estas evidências sugerem um papel até agora desconhecido, ou pelo menos pouco reconhecido, para os eosinófilos. No entanto, doentes com eosinopenia não evidenciam efeitos deletérios associados a este défice ${ }^{18}$, pelo que permanece a questão de quão essenciais são os eosinófilos na homeostasia do organismo, em humanos, e na resposta a infeções do trato respiratório por vírus.

\section{ANTICORPOS MONOCLONAIS ANTI-IL-5/IL-5R}

De acordo com as guidelines do Global Initiative for Asthma 2019 (GINA 2019), o tratamento da asma brônquica é realizado por degraus. No quinto e último degrau incluem-se atualmente, entre outros fármacos, os anticorpos anti-IL-5/IL-5R, aprovados para o tratamen- to adjuvante da asma grave a partir dos 6 anos (mepolizumab) ou dos 18 anos de idade (benralizumab e reslizumab) $)^{19-22}$.

\section{Considerações gerais}

Sabendo-se que a IL-5 constitui o principal estímulo para o crescimento, diferenciação, sobrevivência e ativação dos eosinófilos, os anticorpos monoclonais anti-IL-5/ /IL-5R foram desenvolvidos para o tratamento dos doentes com asma eosinofílica com o objetivo de reduzir a produção, atividade e sobrevivência dos eosinófilos ${ }^{5,6,10}$.

Atualmente existem três fármacos aprovados, o mepolizumab, o reslizumab e o benralizumab, cujos mecanismos de ação diferem entre si. O mepolizumab e o reslizumab ligam-se especificamente à IL-5, interferindo na sua ligação ao recetor no eosinófilo20,22,23. O benralizumab vai atuar através da ligação com elevada afinidade e especificidade à subunidade alfa do recetor da IL-5, expresso especificamente na superfície dos eosinófilos e basófilos, promovendo o reconhecimento destas células pelas células NK. Este processo induz a apoptose celular, por um mecanismo de citotoxicidade mediada por células, dependente de anticorpos ${ }^{21,23,24}$. Adicionalmente, a ligação de benralizumab à subunidade alfa do recetor da IL-5 impede também a ligação da IL-5 ao seu recetor ${ }^{24}$.

Quadro I. Características dos diferentes anticorpos monoclonais anti-IL-5/IL-5R $20-22$

\begin{tabular}{|c|c|c|c|}
\hline & Mepolizumab $100 \mathrm{mg}$ & Benralizumab $30 \mathrm{mg} / \mathrm{ml}$ & Reslizumab $10 \mathrm{mg} / \mathrm{ml}$ \\
\hline Ação & IL-5 & IL-5R & IL-5 \\
\hline Idade & 6 anos ou mais & 18 anos ou mais & 18 anos ou mais \\
\hline Via de administração & Subcutânea* & Subcutânea* & Endovenosa \\
\hline Solução & $\begin{array}{l}\text { Reconstituição } \\
(\mathrm{Iml}-100 \mathrm{mg})\end{array}$ & Pronto a administrar & $\begin{array}{l}\text { Diluir em } 50 \mathrm{ml} \text { de } \mathrm{NaCl} 0,9 \% \text {, } \\
\text { administrar durante } 20-50 \text { minutos }\end{array}$ \\
\hline Dose & $\begin{array}{l}6-11 \text { anos: } 40 \mathrm{mg} \\
\geq 12 \text { anos: } 100 \mathrm{mg}\end{array}$ & $30 \mathrm{mg}$ & $\begin{array}{l}\text { 35-199 kg: conforme tabela do RCM } \\
<35 \mathrm{~kg} \text { ou }>199 \mathrm{~kg}: 3 \mathrm{mg} / \mathrm{kg}\end{array}$ \\
\hline Posologia & $4 / 4$ semanas & $\begin{array}{l}\text { I. }{ }^{a}-3 .^{a} \text { tomas: } 4 / 4 \text { semanas } \\
4 .^{a} \text { toma e seguintes: } 8 / 8 \text { semanas }\end{array}$ & $4 / 4$ semanas \\
\hline
\end{tabular}

* Braço/coxa/abdómen. RCM - resumo das características do medicamento 


\section{Características individuais}

Estes fármacos são semelhantes entre si, apesar de apresentarem algumas particularidades (Quadro I) ${ }^{20-22}$. Todos estão indicados como tratamento adjuvante na asma eosinofílica grave, degrau cinco, e não estão indicados para o tratamento das exacerbações agudas. Apenas o mepolizumab se encontra aprovado para idade pediátrica ${ }^{20-22}$. Relativamente à via de administração, o reslizumab é de administração endovenosa, sendo os restantes administrados por via subcutânea. Em relação à posologia, não é necessário ajuste relativamente a doença renal ou hepática, estando os três contraindicados em caso de hipersensibilidade à substância ativa ou excipientes presentes ${ }^{20-22}$. Desconhece-se se mepolizumab e benralizumab são excretados no leite materno e os dados existentes evidenciam excreção do reslizumab ${ }^{20-22}$. Deste modo, estes fármacos apenas deverão ser administrados a lactantes após avaliação ponderada da relação risco-benefício para a lactante e lactente, com eventual suspensão do aleitamento materno ${ }^{20-22}$. Estes fármacos também não devem ser administrados a mulheres grávidas $^{20-22}$. Todos possuem baixo risco de interações medicamentosas ${ }^{20-22}$. No que concerne aos efeitos secundários, o mais frequentemente descrito para $\circ$ mepolizumab e benralizumab são as cefaleias; em relação ao reslizumab, o efeito secundário mais frequente consiste no aumento transitório e assintomático da creatina fosfoquinase sanguínea ${ }^{20-22}$.

\section{Comparação de eficácia entre fármacos}

Atualmente não estão disponíveis ensaios clínicos a comparar os três fármacos entre si. Os estudos têm comparado cada um dos fármacos contra placebo e as comparações existentes entre os diferentes fármacos são indiretas, ajustadas para as diversas variáveis estudadas através de meta-análises e análise estatística, com as consequentes limitações inerentes a este tipo de abordagem metodológica. Assim, as conclusões deverão ser cautelosas. Outro aspeto relevante prende-se com a existência de conflitos de interesse, uma vez que mui- tas vezes a entidade patrocinadora do estudo tem relação direta com o fármaco em análise, podendo salientar alguns aspetos mais favoráveis relativamente ao fármaco comercializado.

\section{Comparação dos fármacos contra o placebo}

Os ensaios clínicos atualmente disponíveis mostram, de modo consistente e com diferentes magnitudes de resultados, que os anticorpos anti-IL-5/IL-5R têm efeitos favoráveis nos doentes com asma eosinofílica grave. Estes fármacos demonstraram melhoria da função pulmonar $\left(F E V_{1}\right)$, redução do número de exacerbações, efeito poupador de corticoides sistémicos e, ainda, melhoria da qualidade de vida, avaliada pelos resultados dos scores de qualidade de vida (AQLQ - Asthma Quality of Life Questionnaire) e de sintomas (ACQ - Asthma Control Questionnaire), aliado a um perfil de segurança favorável 6,23,25-27.

\section{Comparação dos três fármacos entre si}

Os três estudos incluídos neste artigo de revisão foram financiados por três diferentes entidades responsáveis pela comercialização destes fármacos. $O$ primeiro estudo foi financiado pela Glaxo-Smith Kline (comercializa o mepolizumab), o segundo pela Astrazeneca (comercializa o benralizumab) e o terceiro pela TEVA (comercializa o reslizumab).

O primeiro estudo corresponde a uma indirect treatment comparison entre as populações dos estudos MENSA/ /MUSCA (mepolizumab), SIROCCO/CALIMA (benralizumab) e STUDY 3082/STUDY 3083 (reslizumab) ${ }^{25}$. Nesta análise estatística, os doentes foram subdivididos em subgrupos de acordo com a contagem basal de eosinófilos. São comparados os três fármacos relativamente a taxa de exacerbações, clinicamente significativas (definida como exacerbação com necessidade de tratamento com corticoide sistémico) ou com necessidade de recorrência ao serviço de urgência, o impacto no score de sintomas ACQ e ainda impacto na função pulmonar, avaliado através da melhoria do volume expiratório forçado no primeiro segundo $\left(\mathrm{FEV}_{1}\right)^{25}$. Em relação à redução das 
exacerbações clinicamente significativas, verificou-se uma redução significativa com o mepolizumab em relação a reslizumab e benralizumab em doentes com contagem de eosinófilos superior a 150 células $/ \mathrm{mm}^{3}$, não se tendo encontrado diferenças significativas entre o benralizumab e o reslizumab ${ }^{25}$. Também não foram encontradas diferenças entre os três fármacos na redução do número de exacerbações com necessidade de avaliação no serviço de urgência, independentemente da contagem basal de eosinófilos ${ }^{25}$. Em doentes com contagem de eosinófilos superior a 150 células $/ \mathrm{mm}^{3}$, o mepolizumab associou-se a melhoria dos scores $A C Q$, em comparação com os outros dois fármacos, não se tendo encontrado diferenças significativas entre benralizumab e reslizumab ${ }^{25}$. Relativamente à melhoria da função pulmonar, não se observaram diferenças significativas entre os três fármacos, com exceção do subgrupo de doentes com contagem basal de eosinófilos superior a 400 células $/ \mathrm{mm}^{3}$, nos quais o benralizumab se mostrou superior ${ }^{25}$.

O segundo estudo corresponde a uma matching-ajusted indirect comparison (MAIC) entre as populações dos estudos SIROCCO/CALIMA (benralizumab), MENSA/DREAM (mepolizumab) e STUDY 3082/STUDY 3083 (reslizu$\mathrm{mab})^{28}$. Na comparação entre o benralizumab e o mepolizumab, as variáveis contagem de eosinófilos ( $\geq 300$ células/ $\mu \mathrm{l}$ vs $<300$ células $/ \mu \mathrm{l})$, IgE total $(<30 \mathrm{IU} / \mathrm{ml}$ vs $30-700$ $\mathrm{IU} / \mathrm{ml}$ vs $>700 \mathrm{IU} / \mathrm{ml}$ ), exacerbações nos últimos 12 meses ( 2 vs mais de 2), presença de polipose nasal, índice de massa corporal, sexo e utilização de corticoide oral como manutenção, foram consideradas para ajuste ${ }^{28}$. No entanto, a comparação entre benralizumab e reslizumab não foi passível de realização por, após ajuste das variáveis, se ter obtido uma amostra efetiva de tamanho insuficiente; tal deveu-se em grande parte ao facto de quase todos os doentes incluídos no grupo do benralizumab terem pelo menos duas exacerbações no ano anterior, enquanto no grupo do reslizumab cerca de $60 \%$ apresentava apenas uma exacerbação ${ }^{28}$. Os resultados não mostraram superioridade de nenhum dos fármacos relativamente às variáveis analisadas: taxa de exacerbações clinicamente significativas e com necessidade de avaliação no serviço de urgência e alteração da função pulmonar ${ }^{28}$.

O terceiro estudo corresponde a uma bayesian network meta-analysis dos ensaios clínicos aleatorizados publica$\operatorname{dos}^{29}$. Teve como objetivo realizar uma comparação indireta de eficácia entre reslizumab e benralizumab em populações de doentes com características semelhantes relativas a número de exacerbações prévias, contagem basal de eosinófilos no sangue periférico, gravidade da asma, uso de corticoide oral e uso de corticoide inalado ${ }^{29}$. Os autores referem como limitação desta meta-análise o facto de os estudos com reslizumab incluírem doentes com contagem de eosinófilos $>400$ células $/ \mu \mathrm{L}$ com pelo menos uma exacerbação, enquanto os estudos com benralizumab envolveram doentes com eosinófilos $>150$ células $/ \mu \mathrm{L}$ com pelo menos duas exacerbações prévias ${ }^{29}$. As variáveis analisadas foram a taxa de exacerbações clinicamente significativas, alterações do $\mathrm{FEV}_{1}$, alteração do score de controlo de sintomas ACQ e alteração do score de qualidade de vida $A Q L Q^{29}$. Os resultados obtidos não demonstraram diferenças significativas entre os dois fármacos na redução da taxa de exacerbações clinicamente significativas ou melhoria do $\mathrm{FEV}_{1}$; relativamente à melhoria dos scores ACQ e AQLQ, na posologia recomendada para o benralizumab também não foram encontradas diferenças significativas entres os dois fármacos ${ }^{29}$.

\section{PERSPETIVAS FUTURAS DOS ANTICORPOS MONOCLONAIS ANTI-IL-5/IL-5R}

Apesar de atualmente os anticorpos monoclonais anti-IL-5/IL-5R estarem aprovados pela Agência Europeia do Medicamento (EMA) apenas para o tratamento adjuvante dos doentes com asma eosinofílica grave (mepolizumab, reslizumab, benralizumab), a FDA (US Food and Drug Administration) já aprovou o uso de mepolizumab também em doentes com granulomatose eosinofílica com poliangeíte (síndrome de Churg-Strauss) e vários estudos sugerem que estes agentes poderão vir a ser benéficos também 
noutras patologias eosinofílicas, como a rinossinusite crónica com polipose nasal ${ }^{30}$, doença pulmonar obstrutiva crónica com fenótipo eosinofílico ${ }^{31}$, aspergilose broncopulmonar alérgica ${ }^{32,33}$, síndrome hipereosinofílica ${ }^{34,35}$, esofagite eosinofílica ${ }^{36}$ e dermatite atópica ${ }^{37}$. De referir que a FDA atribuiu o estatuto de medicamento órfão ao mepolizumab para o tratamento de síndrome hipereosinofílica, ao benralizumab para síndrome hipereosinofílica, esofagite eosinofílica e granulomatose eosinofílica com poliangeíte e ao reslizumab para a síndrome hipereosinofílica e esofagite eosinofílica ${ }^{38}$. Estão atualmente em curso ensaios clínicos que procuram testar a aplicabilidade destes fármacos também em outras patologias, nomeadamente o mepolizumab na urticária crónica espontânea (fase I) e o benralizumab na gastrite eosinofílica (fase $2 \mathrm{e}$ 3) e fibrose quística (em processo de recrutamento) ${ }^{39}$.

\section{CONCLUSÃO}

Os eosinófilos produzem uma grande variedade de moléculas, participando na defesa do hospedeiro, mas também em muitas patologias. Estas células são cada vez mais reconhecidas como possuindo um papel fundamental na modulação das respostas imune e inflamatória, tanto local como sistémica. A IL-5 é a principal citocina envolvida na produção, diferenciação, ativação e sobrevivência dos eosinófilos. Os doentes com asma brônquica eosinofílica têm níveis elevados de IL-5 no sangue periférico, expetoração e lavado broncoalveolar. $O$ tratamento farmacológico da asma brônquica prevê a utilização de antagonistas da IL-5/IL-5R no degrau cinco como terapêutica adjuvante. Em comparação com o placebo, os três fármacos demonstraram benefício na melhoria da função pulmonar, redução do número de exacerbações, efeito poupador de corticoides sistémicos e melhoria da qualidade de vida. Tendo em conta a atividade antiviral dos eosinófilos recentemente descrita, a redução da sua contagem pelos anticorpos anti-IL-5/IL-5R poderá afetar negativamente a resposta às infeções virais no doente com asma medicado com estes fármacos, sendo no entanto necessários mais estudos para clarificar esta possibilidade. Não dispomos ainda de estudos comparativos diretos entre os três fármacos, pelo que é difícil atualmente concluir qual a melhor opção terapêutica, devendo a seleção do fármaco ser analisada individualmente para cada doente. Os estudos em curso fazem prever o alargamento das indicações terapêuticas dos anticorpos anti-IL-5/IL-5R a várias outras doenças eosinofílicas, sendo esta uma boa perspetiva de futuro para os doentes afetados por estas patologias.

\section{Conflito de interesses}

Os autores declaram que não existem conflitos de interesses.

\section{Contacto:}

Gonçalo Martins dos Santos goncalommdsantos@gmail.com

\section{REFERÊNCIAS}

I. Takatsu K. Interleukin-5 and IL-5 receptor in health and diseases. Proc Jpn Acad 2011;87:463-85.

2. Kita H, Bochner BS. Biology of Eosinophils. In: Jr. NA, Bochner B, Burks A, Busse W, Holgate S, Lemanske R, et al., eds. Middleton's Allergy Principles and Practice. 8th ed. Elsevier Inc.; 2013;265-79.

3. Pasare C, Medzhitov R. Control of B-cell responses by Toll-like receptors. Nature 2005;438:1-5.

4. Kovalszki A, Weller PF. Eosinophils and Eosinophilia. In: Rich RR, Fleisher TA, Shearer WT, Schroeder HW, JR., Frew AJ, et al., eds. Clinical Immunology: Principles and Practice,. 5th ed. Elsevier Ltd; 2019;349-61.

5. Rosenberg HF, Phipps S, Foster PS. Eosinophil trafficking in allergy and asthma. J Allergy Clin Immunol 2007;119(6):1303-10.

6. Agumadu VC, Ramphul K, Mejias SG, Sonaye R, Sombans S, Lohana P. A review of three new anti-interleukin-5 monoclonal antibody therapies for severe asthma. Cureus 2018;10(8).

7. Nakagome K, Nagata M. Involvement and possible role of eosinophils in asthma exacerbation. Front Immunol 2018;9:I-8.

8. Marta D, Cordeiro CR, Neuparth N. Biologics in asthma - Focusing on subcutaneous formulations. In: Regateiro FS, editor. Severe Asthma. Ist ed. 2018;85-98. 
9. Silva JP, Aboin J, Villarnovo M. Biologics in asthma - Focusing on weigh-adjusted dose intravenous formulations. In: Drummond M, Cordeiro CR, Neuparth N, editors. Severe Asthma. Ist ed. 2018;99-124.

10. MásperoJ. Reslizumab in the treatment of inadequately controlled asthma in adults and adolescents with elevated blood eosinophils: Clinical trial evidence and future prospects. Ther Adv Respir Dis Rev 2017;|I:3|I-25.

II. Ravin KA, Loy M. The Eosinophil in infection. Clin Rev Allerg Immunnol 2016;50:214-27.

12. Chusid MJ, Milwaukee W. Eosinophils : Friends or foes? J Allergy Clin Immunol Pract 2018;6:1439-44.

13. Lee JJ, Jacobsen EA, Mcgarry MP, Schleimer RP, Lee NA. Eosinophils in health and disease: The LIAR hypothesis. Clin Exp Allergy 2010;40:563-75.

14. Marichal, Thomas; Mesnil, Claire; Bureau F. Homeostatic eosinophils: Characteristics and functions. Front Med 2017;4:I-6.

15. Mesnil C, Raulier S, Paulissen G, Xiao X, Birrell MA, Pirottin D, et al. Lung-resident eosinophils represent a distinct regulatory eosinophil subset. J Clin Invest 2016;126:3279-95.

16. Weller PF, Spencer LA. Functions of tissue-resident eosinophils. Nat Rev Immunol 2017;17:746-60.

17. Piñeros YSS, Bal SM., Dijkhuis A, Majoor C, Dierdorp BS, Tamara $D$, et al. Eosinophils capture viruses, a capacity that is defective in asthma. Allergy 2019;74:1898-909.

18. Gleich GJ, Klion AD, Lee JJ, Weller PF. The Consequences of not having eosinophils. Allergy 20I3;68:829-35.

19. Global Initiave for Asthma. Global Strategy for Asthma Management and Prevention, 2019. Available from www.ginasthma.org.

20. Resumo das características do medicamento - RESLIZUMAB [Internet]. [cited 2019 Jul 7]. p. I-3I. Available from: https://www. ema.europa.eu/en/documents/product-information/cinqaero-epar-product-information_pt.pdf

21. Resumo das características do medicamento - FASENRA [Internet]. [cited 2019 Mar 4]. p. I-33. Available from: https://www. ema.europa.eu/en/documents/product-information/fasenra-epar-product-information_pt.pdf

22. Resumo das características do medicamento - NUCALA [Internet]. [cited 2019 Jul 7]. p. I-36. Available from: https://www.ema. europa.eu/en/documents/product-information/nucala-epar-product-information_pt.pdf

23. Bagnasco D, Caminati M, Ferrando M, Aloè T, Testino E, Canonica GW, et al. Anti-IL-5 and IL-5Ra: Efficacy and safety of new therapeutic strategies in severe uncontrolled asthma. Biomed Res Int 2018;2018:I-8.

24. Pelaia C, Calabrese C, Vatrella A, Busceti MT, Garofalo E, Lombardo N, et al. Benralizumab: From the basic mechanism of action to the potential use in the biological therapy of severe eosinophilic asthma. Biomed Res Int 2018;2018:I-9.
25. Busse W, Chupp G, Nagase H, Albers FC, Doyle S, Cand D, et al. Anti-IL-5 treatments in patients with severe asthma by blood eosinophil thresholds: Indirect treatment comparison. J Allergy Clin Immunol Press 2019;143:190-200.e20.

26. Nair P, Bardin P, Humbert M, Murphy KR. Efficacy of intravenous reslizumab in oral corticosteroid e dependent asthma. J Allergy Clin Immunol Pract 2020;8:555-64.

27. Luis AP, Llano D, Cos BG, Domingo C, Urrutia I. Efficacy and safety of reslizumab in patients with severe asthma with inadequate response to omalizumab: A multicenter, open-label pilot study. J Allergy Clin Immunol Pract 2019;7:2277-2283.e2.

28. Bourdin A, Husereau D, Molinari N, Golam S, Siddiqui MK, Lindner $\mathrm{L}$, et al. Matching-adjusted indirect comparison of benralizumab versus interleukin-5 inhibitors: Systematic review. Eur Respir J 2018;52.

29. Casale TB, Pacou M, Mesana L, Farge G, Sun SX, Castro M. Reslizumab compared with benralizumab in patients with eosinophilic asthma: A systematic literature review and network meta-analysis. J Allergy Clin Immunol Pract 2019;7:122-130.el.

30. Kartush AG, Schumacher JK, Shah R, Patadia MO. Biologic agents for the treatment of chronic rhinosinusitis with nasal polyps. Am J Rhinol Allergy 2018.

31. Romero GAF, Beros J, Criner G. Mepolizumab for the prevention of chronic obstructive pulmonary disease exacerbations. Expert Rev Respir Med 2019;13:125-32.

32. Soeda S, To M, Kono Y, Yamawaki S, Tsuzuki R, Katsube O, et al. Case series of allergic bronchopulmonary aspergillosis treated successfully and safely with long-term mepolizumab. Allergol Int 2019;68:377-9.

33. Soeda S, Kono Y, Tsuzuki R, Yamawaki S, Katsube O, To M, et al. Allergic bronchopulmonary aspergillosis successfully treated with benralizumab. J Allergy Clin Immunol Pract 2019;7:1633-5.

34. Schwarz C, Lau S, Parasher K, Staab D, Wahn U, Schwarz C. Mepolizumab - A novel option for the treatment of hypereosinophilic syndrome in childhood. Pediatr Allergy Immunol 2018;29:28-33.

35. Harish A, Schwartz SA. Targeted anti-IL-5 therapies and future therapeutics for hypereosinophilic syndrome and rare eosinophilic conditions. Clin Rev Allergy Immunol 2020;I.

36. Lucendo AJ. Pharmacological treatments for eosinophilic esophagitis: current option and emerging therapies. Expert Rev Clin Immunol 2020;16:63-77.

37. Kang EG, Narayana PK, Pouliquen IJ, Lopez MC, Ferreira-Cornwell MC, Getsy JA. Efficacy and safety of mepolizumab administered subcutaneously for moderate to severe atopic dermatitis. Allergy $2019 ; 1-4$.

38. FDA - Orphan Drug [Internet]. [cited 2020 Feb 10]. Available from: https://www.accessdata.fda.gov/scripts/opdlisting/oopd/

39. Clinical Trials [Internet]. [cited 2020 Feb II]. Available from: https://clinicaltrials.gov 